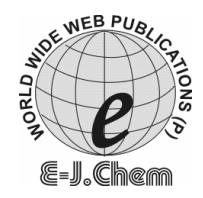

http://www.e-journals.net
ISSN: 0973-4945; CODEN ECJHAO

E-Journal of Chemistry

2010, 7(3), 1029-1032

\title{
Evaluation of Haematological and Immunological Status in Type 2 Diabetics
}

\author{
A. SOHNA CHANDRA PACKIAVATHY* and M. RAMALINGAM \\ *Department of Biochemistry, PRIST University, Thanjavur-614904, India. \\ Center for Research and Development, PRIST University, \\ Vallam, Thanjavur - 613103, India. \\ sohnachandra@gmail.com
}

Received 20 October 2009; Accepted 15 December 2009

\begin{abstract}
Type 2 diabetes is a heterogeneous disorder involving impairment of both insulin secretion and insulin action. The immunological and haematological statuses during normal and diseased conditions have been studied. The study groups consisted of 220 patients (110 males, 110 females) and 220 age and sex matched control subjects (110 males, 110 females). The values of $\operatorname{IgG}, \operatorname{IgM}$, IgE and $\operatorname{IgA}$ were found to be significantly increased. Leucocyte count and erythrocyte sedimentation rate were also found to be increased in the type 2 diabetics as compared to controls. The study suggests that variation in the levels of immunoglobulins and cell count may be involved in the pathogenesis of type 2 diabetes mellitus.
\end{abstract}

Keywords: Type 2 diabetes mellitus, Haematology, Immunoglobulins.

\section{Introduction}

Type 2 diabetes is an incurable, chronic endocrine disorder that affects the body's ability to convert food into energy. Hyperglycemia is the hallmark of diabetes mellitus. Diabetics are likely to experience acute metabolic complications. They are prone to develop micro and macrovascular complications compared to non-diabetics. Type 2 diabetes is characterized by insulin resistance, decreased pancreatic $\beta$-cell function and elevated hepatic glucose output $(\mathrm{HGO})^{1-3}$.

Insulin resistance typically becomes worse with the progression of diabetes because of dysregulation of lipid and carbohydrate metabolism. Impaired $\beta$-cell function in these patients as evidenced by altered pulsatility of insulin release, loss of first phase insulin release and reduced insulin release in response to a glucose load plays an important role in the expression of the disease. Finally increased HGO correlates well with the fasting plasma glucose levels and is the primary cause of fasting hyperglycemia in type 2 diabetes $^{1-3}$. 
Immune dysfunction is prominently present in type 2 diabetes. There is marked variation in the levels of immunoglobulins ${ }^{4}$. Cell count is significantly altered ${ }^{5}$ and ESR is also affected by diabetes ${ }^{6}$.

\section{Experimental}

The study group consisted of uncontrolled type 2 diabetes mellitus patients $(n=220,110$ males, 110 females) attending Samuel Clinic, Thanjavur. They were freshly diagnosed diabetics and were not under medication for the disease previously. Age and sex matched control subjects ( $\mathrm{n}=220,110$ males, 110 females) were clinically non diabetic and normal as given in Table 1.

Table 1. Case history of the chronic type 2 diabetic subjects investigated.

\begin{tabular}{lcc}
\hline \multicolumn{1}{c}{ Subjects } & Control & Type 2 diabetics \\
\hline Sex & 110 Males +110 Females & 110 Males + 110 Females \\
Age, years & $45-70$ & $45-70$ \\
Height, Inches & $5^{\prime} 6^{\prime \prime}$ & $56^{\prime \prime}$ \\
Body weight, kg & 60 & 75 \\
BMI, Kg/m & 21.3 & 26.6 \\
Duration of diabetes, years & - & $6-20$ \\
Complications, $\%$ & - & 50 \\
Hypertension & - & 30 \\
Coronary artery disease & - & 10 \\
Peripheral Vascular disease & - & 50 \\
Neuropathy & - & 20 \\
Nephropathy & - & 10 \\
Retinopathy & - & - \\
Cerebro vascular disease & & \\
\hline
\end{tabular}

Serum and whole blood were utilized for immunological and haematological studies. Total cell count was determined by using a haemocytometer, differential count was determined by Leishmann stain and ESR was estimated by Westergren method.

Immunoglobulin quantitative test is based on a solid phase enzyme linked immunosorbent assay (ELISA). The sample containing antigen was added to antibody coated microtiter well and allowed to react. The free antibodies were washed away and then an enzyme Horse Radish Peroxidase (HRP) conjugated with goat antihuman antibody reagent was added along with the substrate. The colour developed was estimated in an ELISA reader.

\section{Results and Discussion}

Elevated levels of $\operatorname{IgG}, \operatorname{IgM}, \operatorname{IgA}$ and $\operatorname{IgE}$ have been observed to be the predominant markers of type 2 diabetes (Table 2). More than this, an elevated level of agranulocytes and granulocytes are the ubiquitous findings observed in type 2 diabetics. ESR was found to be above the normal range.

Serum gamma globulin is a non specific measure of humoral immune system. IgG concentration was found to be high in type 2 diabetics. This suggests that immune function or activation play an important role in the development of type 2 diabetes. Hence elevated level of gamma globulin in blood can predict type 2 diabetes $^{7}$. 
Table 2. Clinical characteristics of study subjects (Values are Mean \pm SD).

\begin{tabular}{lll}
\hline Parameter & Control & Type 2 Diabetics \\
\hline IgG, mg/dL & $1131.84 \pm 290.12$ & $1835.22 \pm 97.09^{* *}$ \\
IgM, mg/dL & $162.06 \pm 59.18$ & $388.5 \pm 106.56^{* *}$ \\
IgA, mg/dL & $195.51 \pm 80.73$ & $474.10 \pm 73.39^{* *}$ \\
IgE, mg/dL & $60.80 \pm 20.60$ & $329.54 \pm 102.14^{* *}$ \\
RBC, million /cu. mm of cells & $5.29 \pm 0.61$ & $5.47 \pm 3.45$ \\
WBC (/cu.mm of cells) & $6875.14 \pm 1648.12$ & $13753.96 \pm 1813.95^{* *}$ \\
Eosinophil, \% & $1.96 \pm 0.77$ & $12.35 \pm 6.33^{* *}$ \\
Neutrophil, \% & $49.41 \pm 6.68$ & $74.69 \pm 10.55^{* *}$ \\
Basophil, \% & $0.6 \pm 0.5$ & $0.47 \pm 0.5$ \\
Monocytes, \% & $5.92 \pm 1.54$ & $16.92 \pm 6.61^{* *}$ \\
Lymphocytes, \% & $29.40 \pm 5.82$ & $57.34 \pm 10.77^{* *}$ \\
ESR, mm/h & $9.62 \pm 3.06$ & $25.70 \pm 8.28^{* *}$ \\
\hline & $* * P<0.001$ &
\end{tabular}

The values of $\operatorname{IgA}$ and $\operatorname{IgM}$ were significantly elevated. The increase is directly proportional to the progression of the disease $\mathrm{e}^{8}$. IgE was also found to be above the normal range. High levels of IgE elevate glucose and disrupt the homeostasis of endogenous protein.

In vitro trials indicate that a mean glucose level $>200 \mathrm{mg} / \mathrm{dL}$ cause leucocyte dysfunction $^{9-11}$. In our investigation also leucocyte count is in an elevated state. This suggests that white blood cell count is a predictor of glucose tolerance and Insulin sensitivity. White cell count is positively associated with obesity ${ }^{12}$.

Chronic Inflammation plays a prominent role in the pathogenesis of type 2 diabetes mellitus ${ }^{13}$. In our study the eosinophils and neutrophils were found to be above the normal range and they are involved in inflammation ${ }^{14}$. The basophil count was found to be within the normal range in type 2 diabetics. The number of monocytes and lymphocytes were found to be higher due to inflammatory response.

ESR, which is a measure of the tendency of red cells to aggregate was used to screen for the presence of hidden inflammation. ESR was found to be elevated and IgM is a major determinant of it. ESR is directly associated with diabetes and can be considered as an independent marker of diabetes ${ }^{15}$. A significant increase in ESR also directs physicians' attention to coronary disease and its consequences ${ }^{16}$. There remarkable elevation in the above stated immunoglubulins and cells explain the immune dysfunction in severe type 2 diabetics.

\section{Conclusion}

It is thus concluded that, immunological processes in the pathogenesis of type 2 diabetes are capable of stimulating the production of immunoglobulins. Granulocytes and agranulocytes play pivotal role in the pathogenesis of type 2 diabetes. Thus, the quantification play pivotal role in the pathogenesis of type 2 diabetes. Thus the quantification of immunoglobulins and the cells of the blood system may play a prominent role in the diagnosis and progression of type 2 diabetes.

\section{References}

1. Defronzo R A, Bonadonna R C and Ferrannini E, Diabetes Care, 1992, 15, 318 - 368.

2. Reaven G M, Annu Rev Med., 1993, 44, 121-131.

3. Saltiel A R and Olysky J M, Diabetes, 1996, 45, 1661 - 1669. 
4. Bakoush O, Tencer J, Tapia J, Rippe B and Torffvit O, Kidney Int., 2002, 61, 203-208.

5. Bagdade J, Root R and Bulger R, Diabetes, 1974, 23, 9-15.

6. Danesh J, Collins R, Peto R and Lowe G D O, Eur Heart J., 2000, 21, 515-520.

7. Lindray K S, Krakoft J, Hanson R L, Bennett P H and Knowler W C, Diabetes 2001, 50, 1598 - 1603.

8. Ardawi M S, Nasrat H A and Bahnassy A A, Diabet Med., 1994, 11, 384 - 387.

9. Vozarova B, Weyer C, Lindsay R S, Pratley R E, Bogardus C and Tataranni P A, , Diabetes, 2002, 51, 455- 461.

10. Stemme S, Faber B and Holm J, Wiklund O, Witztum J L and Hansson G K, Proc Natl Acad Sci, USA, 1995, 92, 3893 - 3897.

11. Bagdade J, Root R and Bulger R, Diabetes, 1974, 23, 9-15.

12. Pratley R E, Wilson C and Bogardus C, Obes Res., 1995, 3, 563 - 571.

13. Marette A, Current Opinion in Clinical Nutrition and Metabolic Care, 2002, 5, 377-383.

14. Schmidt M I, Duncan B B, Sharrelt A R, Lindberg G, Sarage P J, Offenbacher S, Azambija M I, Tracy K P and Heiss G, Lancet, 1999, 353, 1649 - 1652.

15. Erikesen G, Liestol K and Bjornhost J V, Stormorken H, Thaulow E and Erikssen J, Eur Heart J, 2000, 21(19), 1614 - 1620.

16. Andresdoffir M B, Sigfusson N, Sigvaldason H and Gudnason V, Am J Epidemiol., 2003, 158, 844-51. 


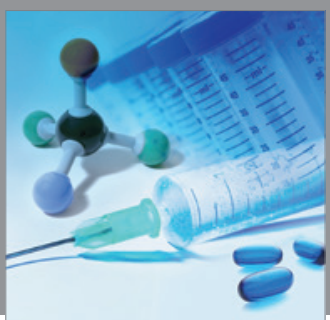

International Journal of

Medicinal Chemistry

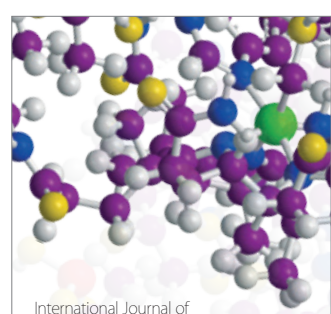

Carbohydrate Chemistry

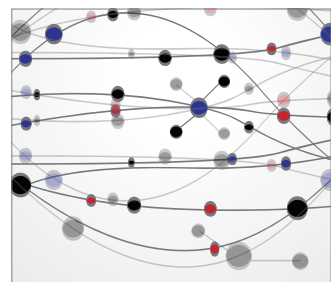

The Scientific World Journal
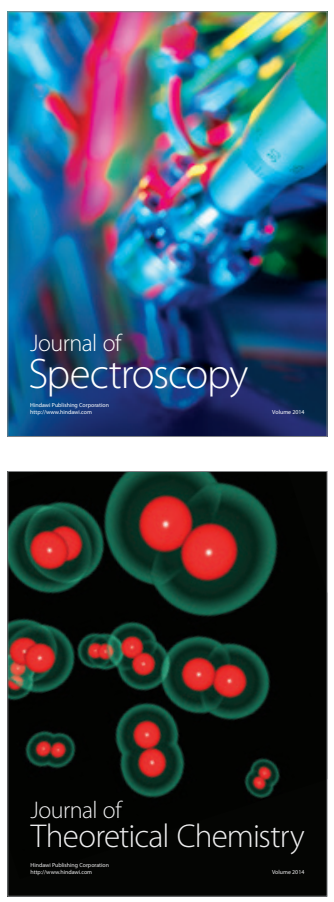
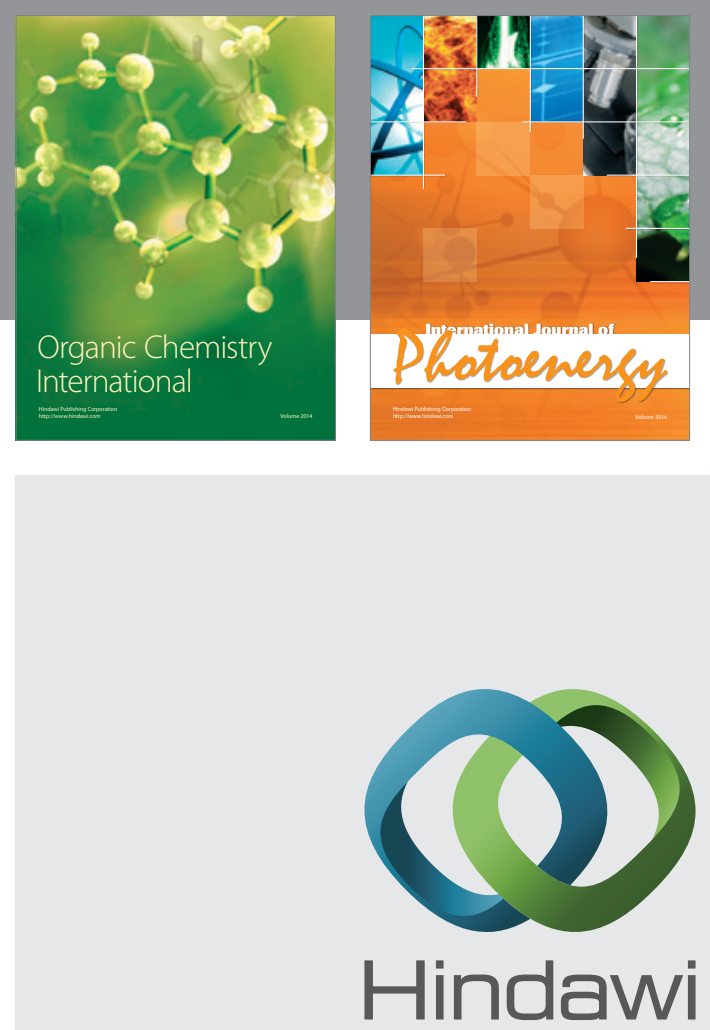

Submit your manuscripts at

http://www.hindawi.com
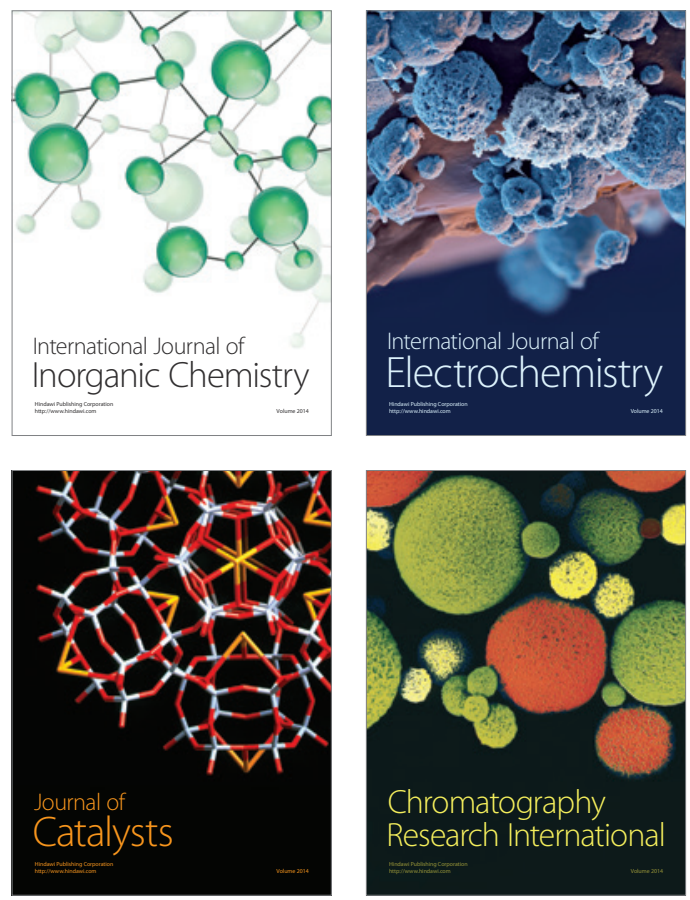
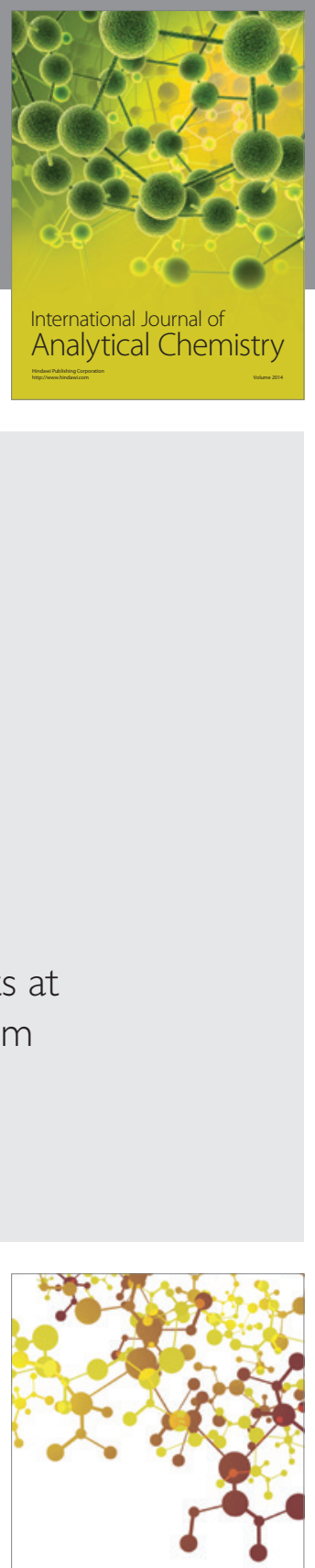

Journal of

Applied Chemistry
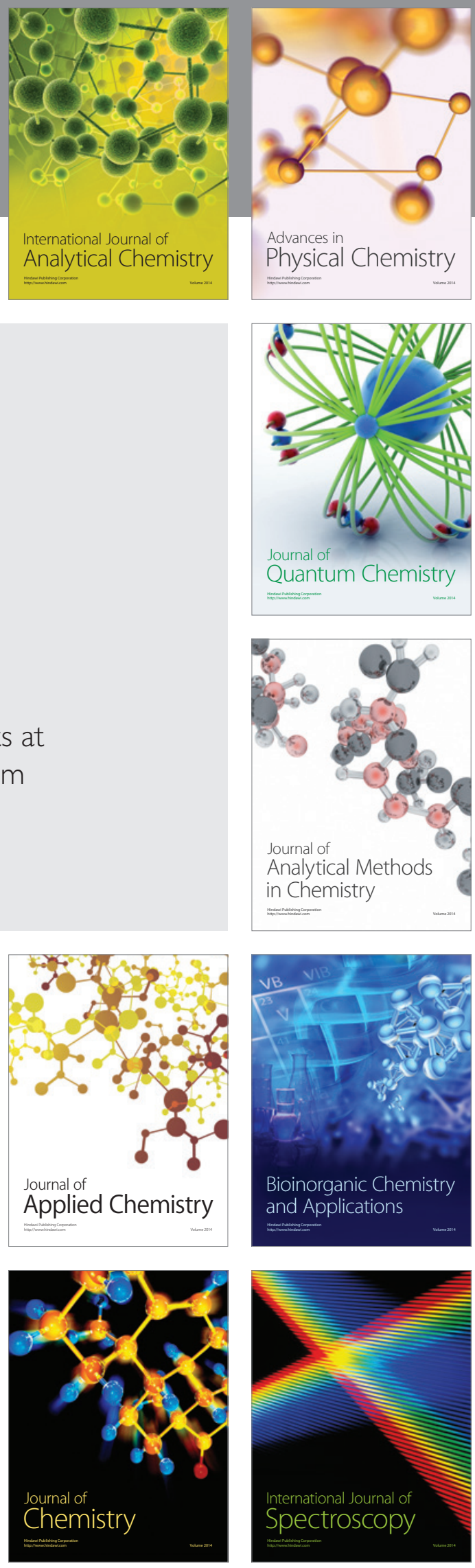